\title{
Risk Factors for Vitamin D, Zinc, and Selenium Deficiencies in Korean Patients with Inflammatory Bowel Disease
}

\author{
Yoo Min Han ${ }^{1,2}$, Hyuk Yoon ${ }^{3}$, Soo Lim³ ${ }^{3}$, Mi-Kyung Sung ${ }^{4}$, Cheol Min Shin ${ }^{3}$, Young Soo Park ${ }^{3}$, Nayoung Kim ${ }^{1,3}$, Dong Ho \\ Lee $^{1,3}$, and Joo Sung Kim ${ }^{1,2}$ \\ ${ }^{1}$ Department of Internal Medicine and Liver Research Institute, Seoul National University College of Medicine, ${ }^{2}$ Department of Internal \\ Medicine and Healthcare Research Institute, Healthcare System Gangnam Center, Seoul National University Hospital, Seoul, ${ }^{3}$ Department of \\ Internal Medicine, Seoul National University Bundang Hospital, Seongnam, and ${ }^{4}$ Department of Food and Nutrition, Sookmyung Women's \\ University, Seoul, Korea
}

See editorial on page 317.

Background/Aims: Studies on the micronutrient status of Asian patients with inflammatory bowel disease (IBD) are scarce. We evaluated the prevalence of micronutrient deficiency and verified the risk factors for micronutrient deficiency in Korean patients with IBD. Methods: We measured the serum levels of 25-hydroxyvitamin D3 [25-(OH)D], zinc, and selenium to analyze the clinical risk factors for micronutrient levels below the reference values. In addition, we compared the 25- $(\mathrm{OH}) \mathrm{D}$ levels of patients with IBD to those of age- and sex-matched healthy controls. Results: Among the 83 patients, 74 (89.2\%) had suboptimal serum 25-(OH)D levels. The mean plasma $25-(\mathrm{OH}) \mathrm{D}$ level in patients with IBD was significantly reduced compared to that of the healthy controls (12.3 $\pm 6.2 \mathrm{ng} / \mathrm{mL}$ vs $20.0 \pm 6.7 \mathrm{ng} / \mathrm{mL}$; $p<0.001)$. The proportions of patients with lower serum zinc and selenium levels were $39.0 \%$ and $30.9 \%$, respectively. Female sex $(p=0.012)$ and Crohn's disease $(p=0.012)$ were associated with vitamin D deficiency. Patients younger than 40 years were at increased risk for zinc deficiency $(p=0.045)$. Female sex $(p=0.015)$ and low serum albumin level $(<3.3$ $g / d L)(p=0.047)$ were risk factors for selenium deficiency. Conclusions: Many Korean patients with IBD have vitamin $D$, zinc, and selenium deficiencies, suggesting the necessity for monitoring levels of these micronutrients. (Gut Liver 2017;11:363-369)

Key Words: Inflammatory bowel diseases; Vitamin D; Selenium; Zinc; Deficiency

\section{INTRODUCTION}

Inflammatory bowel disease (IBD) is a chronic relapsing disease that causes significant morbidity. ${ }^{1}$ Malnutrition is one of its major comorbidities and is present in up to $85 \%$ of patients with IBD. ${ }^{2-4}$ Malnutrition can be classified as macronutrient deficiency and micronutrient deficiency. Macronutrient deficiency, which means protein energy malnutrition, usually occurs in patients with active and severe disease. Many novel treatment modalities such as immunomodulators and biologics have been introduced, and a great proportion of IBD cases are now in clinical remission. Patients with IBD in remission usually have a macronutrient intake similar to that of healthy controls. As a consequence, the prevalence of macronutrient deficiency has decreased. ${ }^{5}$ However, micronutrient deficiency can occur in the mild form of IBD or in the remission state of IBD; numerous forms of micronutrient deficiencies have been reported. ${ }^{2,6,7}$ Evaluation of micronutrient status at least once per year has been recommended; ${ }^{8}$ however, most clinicians focus little attention on nutritional support in patients with IBD.

Vitamin D is a fat-soluble vitamin important for normal bone metabolism because it facilitates intestinal calcium absorption and increases osteoblastic differentiation. Vitamin D deficiency in adults can result in osteopenia and osteoporosis, induce osteomalacia and muscle weakness, and increase the risk of fracture. ${ }^{9}$ Patients with IBD are at increased risk for vitamin D deficiency. ${ }^{10-13}$ Long-term use of corticosteroids in patients with IBD increases the risk of osteoporosis; therefore, maintenance of appropriate vitamin D levels might be more critical for these patients. In addition, some studies suggest that vitamin D deficiency is not the result of disease and instead has a substantial

Correspondence to: Hyuk Yoon

Department of Internal Medicine, Seoul National University Bundang Hospital, 82 Gumi-ro 173beon-gil, Bundang-gu, Seongnam 13620, Korea

Tel: +82-31-787-7042, Fax: +82-31-787-4051, E-mail: bodnsoul@hanmail.net

Received on July 4, 2016. Revised on September 9, 2016. Accepted on September 22, 2016. Published online February 17, 2017

pISSN 1976-2283 eISSN 2005-1212 https://doi.org/10.5009/gnl16333

@ This is an Open Access article distributed under the terms of the Creative Commons Attribution Non-Commercial License (http://creativecommons.org/licenses/by-nc/4.0) which permits unrestricted non-commercial use, distribution, and reproduction in any medium, provided the original work is properly cited. 
role in the pathogenesis of IBD. ${ }^{14,15}$ Therefore, monitoring and appropriate supplementation of vitamin D are important.

Another essential micronutrient, zinc, has several physiologic roles in growth and immune system modulation. ${ }^{16}$ Zinc deficiency can cause susceptibility to infection, poor growth, and impaired wound healing. Approximately 15\% of patients with IBD reportedly have zinc deficiency. ${ }^{17}$ In previous studies, zinc deficiency was shown to affect inflammation in IBD by aggravating mucosa leakage, by increasing the number of proinflammatory cells, and by modulating inflammatory cytokine response. $^{18}$

Selenium is a nonmetal trace element that acts as a catalyst and antioxidant. ${ }^{19}$ Selenium levels are reportedly decreased in patients with Crohn's disease (CD), and a low selenium concentration may facilitate inflammatory and immune responses. ${ }^{20}$ In another experiment, selenium deficiency worsened colitis and promoted tumorigenesis. ${ }^{21}$ Selenium supposedly modulates the expression of the nuclear factor $\kappa \mathrm{B}$ pathway and influences development of inflammation and carcinogenesis. ${ }^{22}$

The role of micronutrients has been investigated actively in IBD, leading to the discovery of problems in the evaluation of micronutrient status and in the correction of micronutrient deficiency. The majority of recent studies of micronutrient deficiency were performed in America and Europe. These studies reported that $30.8 \%$ to $49.8 \%$ of IBD patients had vitamin D deficiency ${ }^{23,24}$ and prevalence of zinc deficiency in IBD patients were reported as 15\%. ${ }^{17}$ In another study performed in France, selenium concentration was significantly decreased in CD patients. ${ }^{20}$ Little information is available regarding the micronutrient status of Asian patients with IBD. The aim of this study was to evaluate the prevalence of micronutrient (vitamin D, zinc, and selenium) deficiency in Korean patients with IBD and to verify the factors that affect micronutrient deficiency in patients with IBD by using multivariate analysis.

\section{MATERIALS AND METHODS}

\section{Study subjects}

Between 2013 and 2015, patients diagnosed with IBD at Seoul National University Bundang Hospital who had undergone blood testing for serum vitamin D, zinc, and selenium were enrolled. These micronutrients were measured during the first or second visit to our clinic if there were no contraindications and if patient did not refuse the laboratory examination. Pregnant and lactating patients were excluded. Patients with a predisposing vitamin D-related disorder, such as rickets, primary hyperparathyroidism, chronic kidney disease, and malignancy, were also excluded. We reviewed the medical records of these patients. Data regarding age, sex, type of IBD, duration of illness, smoking status, history of intestinal resection, and current medication were collected. Serum levels of C-reactive protein (CRP) and albumin were also evaluated. Reference values for
CRP and albumin were 0 to $0.5 \mathrm{mg} / \mathrm{dL}$ and 3.3 to $5.2 \mathrm{~g} / \mathrm{dL}$, respectively.

\section{Definition of micronutrient deficiency}

Vitamin D level was measured as serum 25-hydroxyvitamin D3 [25-(OH)D] using ultra performance liquid chromatographytandem mass spectrometry. ${ }^{25}$ Vitamin D deficiency was defined as a 25-(OH)D level of less than $10 \mathrm{ng} / \mathrm{mL}$ (50 nmol/L). A 25$(\mathrm{OH}) \mathrm{D}$ level of 10 to $19 \mathrm{ng} / \mathrm{mL}$ (50 to $75 \mathrm{nmol} / \mathrm{L}$ ) was defined as vitamin D insufficiency, and a level of $\geq 20 \mathrm{ng} / \mathrm{mL}$ was considered to indicate a sufficient level of vitamin D. ${ }^{9,26}$

Selenium and zinc levels were measured using inductively coupled plasma mass spectrometry. Zinc was considered deficient when the serum level was $\leq 70 \mu \mathrm{g} / \mathrm{dL} .{ }^{16}$ Selenium levels $\leq 95 \mu \mathrm{g} / \mathrm{L}$ were classified as selenium deficiency. ${ }^{19}$

\section{Healthy controls and vitamin D status}

Healthy controls were selected from the cohort involved in a previous study performed by Lim et al. ${ }^{27}$ This cohort included participants who had undergone routine physical examination at Seoul National University Bundang Hospital. The healthy control pool was established using this cohort, and patients were matched to the healthy controls at a 1:1 ratio according to age and sex.

\section{Statistical analysis}

SPSS for Windows version 18.0 (SPSS Inc., Chicago, IL, USA) was used for the statistical analysis. Baseline characteristics of the patients were presented as descriptive data. The vitamin D levels of the patients with IBD and the healthy controls were compared using Student t-test. Univariate binary logistic regression analysis was used to identify possible covariates as significant risk factors for micronutrient deficiency. Variables with $\mathrm{p}<0.10$ were then subjected to multivariate logistic regression analysis to identify independent contributors. All results were considered statistically significant when $\mathrm{p}<0.05$.

\section{Ethical standards}

This study was approved by the Institutional Review Board of Seoul National University Bundang Hospital (IRB number: B-1512/328-114) and was conducted in accordance with the Declaration of Helsinki.

\section{RESULTS}

\section{Baseline characteristics}

A total of 83 patients with IBD were enrolled in the study (Table 1). Among them, 64 (77.1\%) were men and the median age was 32 years. Thirty-four (41.0\%) were diagnosed with CD and 49 (59.0\%) were diagnosed with ulcerative colitis. The median duration of illness was 5 months. Five patients (6.0\%) had undergone intestinal resection. Micronutrient status of 83 IBD 
Table 1. Clinical Characteristics of the 83 Patients with Inflammatory Bowel Disease

\begin{tabular}{|c|c|}
\hline Variable & Value \\
\hline Male sex & $64(77.1)$ \\
\hline Age, yr & $32(16-70)$ \\
\hline \multicolumn{2}{|l|}{ Type of IBD } \\
\hline Crohn's disease & $34(41.0)$ \\
\hline Ulcerative colitis & 49 (59.0) \\
\hline Duration of illness, mo & $5(1-228)$ \\
\hline \multicolumn{2}{|l|}{ Disease location } \\
\hline Crohn's disease & $34(100)$ \\
\hline Terminal ileum & $10(29.4)$ \\
\hline Colon & $1(2.9)$ \\
\hline Ileocolon & $23(67.6)$ \\
\hline Ulcerative colitis & 49 (100.0) \\
\hline Proctitis & $16(32.7)$ \\
\hline Left sided & $10(20.4)$ \\
\hline Pancolitis & $23(46.9)$ \\
\hline \multicolumn{2}{|l|}{ Smoking status } \\
\hline Never & $46(56.8)$ \\
\hline Past & $19(23.5)$ \\
\hline Current & $16(19.8)$ \\
\hline History of intestinal resection & $5(6.0)$ \\
\hline \multicolumn{2}{|l|}{ Current medication } \\
\hline Corticosteroids & $26(31.3)$ \\
\hline Immunomodulators & $9(10.8)$ \\
\hline TNF- $\alpha$ inhibitors & $3(3.6)$ \\
\hline Serum CRP, mg/dL & $0.5(0-13.9)$ \\
\hline Serum albumin, g/dL & $4.2(2.4-4.9)$ \\
\hline
\end{tabular}

Data are presented as number (\%) or median (range).

IBD, inflammatory bowel disease; TNF, tumor necrosis factor; CRP, C-reactive protein.

patients was listed in Table 2.

\section{Vitamin D status of IBD patients and healthy controls}

Sixty-six healthy controls were available for matching with the study patients. The mean serum level of $25-(\mathrm{OH}) \mathrm{D}$ in patients with IBD was significantly lower than that of healthy controls (12.3 $\pm 6.2 \mathrm{ng} / \mathrm{mL}$ vs $20.0 \pm 6.7 \mathrm{ng} / \mathrm{mL} ; \mathrm{p}<0.001$ ) (Fig. 1).

\section{Factors affecting vitamin $D$ deficiency}

Seventy-four patients (89.2\%) had suboptimal levels of serum 25-(OH)D (vitamin D insufficiency, 49.4\% and vitamin D deficiency, 39.8\%). In the univariate binary logistic regression analysis, female sex, age younger than 40 years, and diagnosis of $\mathrm{CD}$ were possible risk factors for vitamin $\mathrm{D}$ deficiency. These variables were included in the multivariate logistic regression analysis; female sex (relative risk [RR], 4.735; 95\% confidence interval [CI], 1.414 to 15.857 ; $\mathrm{p}=0.012$ ) and diagnosis of $\mathrm{CD}(\mathrm{RR}$,
Table 2. Micronutrient Status of the 83 Patients with Inflammatory Bowel Disease

\begin{tabular}{lc}
\hline \multicolumn{1}{c}{ Variable } & Value \\
\hline Serum vitamin D, mg/mL & $11.9 \pm 6.0$ \\
Serum vitamin D status, $\mathrm{ng} / \mathrm{mL}$ & \\
Optimal $(\geq 20)$ & $9(10.8)$ \\
Insufficiency $(10-19)$ & $41(49.4)$ \\
Deficiency $(<10)$ & $33(39.8)$ \\
Serum zinc, $\mu \mathrm{g} / \mathrm{dL}$ & $76.6 \pm 14.9$ \\
Serum zinc status, $\mu \mathrm{g} / \mathrm{dL}$ & \\
Optimal $(\geq 70)$ & $51(61.0)$ \\
Deficiency $(<70)$ & $32(39.0)$ \\
Serum selenium, $\mu \mathrm{g} / \mathrm{L}$ & $101.5 \pm 16.7$ \\
Serum selenium status, $\mu \mathrm{g} / \mathrm{L}$ & \\
Optimal $(\geq 95)$ & $58(69.1)$ \\
Deficiency $(<95)$ & $25(30.9)$ \\
\hline
\end{tabular}

Data are presented as mean \pm SD or number $(\%)$.

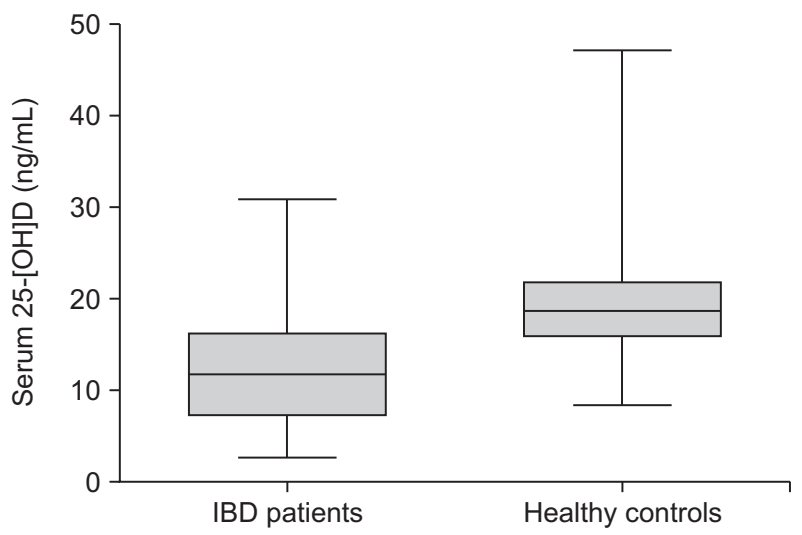

Fig. 1. Serum 25-hydroxyvitamin D3 (25-[OH]D) levels in inflammatory bowel disease (IBD) patients and healthy controls.

4.012; 95\% CI, 1.352 to $11.900 ; \mathrm{p}=0.012$ ) were associated with vitamin D deficiency (Table 3).

\section{Factors affecting zinc deficiency}

There were 32 patients (38.5\%) with serum zinc levels below reference values $(70 \mu \mathrm{g} / \mathrm{dL})$. Patients younger than 40 years, those diagnosed with $\mathrm{CD}$, current users of corticosteroids, and those with serum CRP levels $>0.5 \mathrm{mg} / \mathrm{dL}$ were at higher risk for zinc deficiency by univariate binary logistic regression. In the multivariate logistic regression analysis, patients younger than 40 years were at increased risk for zinc deficiency (RR, 3.683; 95\% CI, 1.152 to $11.777 ; \mathrm{p}=0.028$ ) (Table 4).

\section{Factors affecting selenium deficiency}

Twenty-five patients (30.1\%) had serum selenium levels below reference values $(95 \mu \mathrm{g} / \mathrm{L})$. Possible covariates as significant risk factors for selenium deficiency in the univariate analysis 
Table 3. Univariate and Multivariate Analysis of Risk Factors for Vitamin D Deficiency in Patients with Inflammatory Bowel Disease

\begin{tabular}{|c|c|c|c|c|}
\hline \multirow{2}{*}{ Variable } & \multirow{2}{*}{$\begin{array}{l}\text { No. of vitamin D } \\
\text { deficiency (\%) }\end{array}$} & \multirow{2}{*}{$\begin{array}{c}\text { Univariate analysis } \\
\text { p-value }\end{array}$} & \multicolumn{2}{|c|}{ Multivariate analysis } \\
\hline & & & Relative risk (95\% CI) & $\mathrm{p}$-value \\
\hline Sex & & 0.066 & & 0.012 \\
\hline Male & $22(34.4)$ & & 1 & \\
\hline Female & $11(57.9)$ & & 4.735 (1.414-15.857) & \\
\hline Age, yr & & 0.086 & & 0.307 \\
\hline$\geq 40$ & $9(28.1)$ & & 1 & \\
\hline$<40$ & $24(47.1)$ & & $1.755(0.597-5.163)$ & \\
\hline Type of IBD & & 0.022 & & 0.012 \\
\hline Ulcerative colitis & $14(28.6)$ & & 1 & \\
\hline Crohn's disease & 19 (55.9) & & $4.012(1.352-11.900)$ & \\
\hline
\end{tabular}

CI, confidence interval; IBD, inflammatory bowel disease.

Table 4. Univariate and Multivariate Analysis of Risk Factors for Zinc Deficiency in Patients with Inflammatory Bowel Disease

\begin{tabular}{|c|c|c|c|c|}
\hline \multirow{2}{*}{ Variable } & \multirow{2}{*}{$\begin{array}{c}\text { No. of zinc } \\
\text { deficiency (\%) }\end{array}$} & \multirow{2}{*}{$\begin{array}{c}\text { Univariate analysis } \\
\text { p-value }\end{array}$} & \multicolumn{2}{|c|}{ Multivariate analysis } \\
\hline & & & Relative risk (95\% CI) & p-value \\
\hline Age, yr & & 0.004 & & 0.028 \\
\hline$\geq 40$ & $6(19.4)$ & & 1 & \\
\hline$<40$ & $26(51.0)$ & & $3.683(1.152-11.777)$ & \\
\hline Type of IBD & & 0.008 & & 0.143 \\
\hline Ulcerative colitis & $13(27.1)$ & & 1 & \\
\hline Crohn's disease & $19(55.9)$ & & $2.209(0.765-6.378)$ & \\
\hline Current use of corticosteroids & & 0.061 & & 0.152 \\
\hline No & $14(53.8)$ & & 1 & \\
\hline Yes & $18(32.1)$ & & $2.213(0.745-6.568)$ & \\
\hline Serum CRP, mg/dL & & 0.087 & & 0.262 \\
\hline$\leq 0.5$ & $13(30.2)$ & & 1 & \\
\hline$>0.5$ & $19(48.7)$ & & $1.837(0.635-5.313)$ & \\
\hline
\end{tabular}

CI, confidence interval; IBD, inflammatory bowel disease; CRP, C-reactive protein.

Table 5. Univariate and Multivariate Analysis of Risk Factors for Selenium Deficiency in Patients with Inflammatory Bowel Disease

\begin{tabular}{|c|c|c|c|c|}
\hline \multirow{2}{*}{ Variable } & \multirow{2}{*}{$\begin{array}{l}\text { No. of selenium } \\
\text { deficiency (\%) }\end{array}$} & \multirow{2}{*}{$\begin{array}{c}\text { Univariate analysis } \\
\text { p-value }\end{array}$} & \multicolumn{2}{|c|}{ Multivariate analysis } \\
\hline & & & Relative risk $(95 \% \mathrm{CI})$ & p-value \\
\hline Sex & & 0.019 & & 0.015 \\
\hline Male & $15(24.2)$ & & 1 & \\
\hline Female & $10(52.6)$ & & $4.871(1.352-17.544)$ & \\
\hline Current use of corticosteroids & & 0.041 & & 0.360 \\
\hline No & $13(23.6)$ & & 1 & \\
\hline Yes & $12(46.2)$ & & $1.722(0.537-5.519)$ & \\
\hline Serum CRP, mg/dL & & 0.017 & & 0.108 \\
\hline$\leq 0.5$ & $8(19.0)$ & & 1 & \\
\hline$>0.5$ & 17 (43.6) & & $2.724(0.803-9.240)$ & \\
\hline Serum albumin, g/dL & & 0.001 & & 0.047 \\
\hline$\geq 3.3$ & $18(24.7)$ & & 1 & \\
\hline$<3.3$ & 7 (87.5) & & $10.346(1.035-103.447)$ & \\
\hline
\end{tabular}

$\mathrm{CI}$, confidence interval; CRP, C-reactive protein. 
were female sex, current use of corticosteroids, serum CRP levels $>0.5 \mathrm{mg} / \mathrm{dL}$, and serum albumin levels $<3.3 \mathrm{~g} / \mathrm{dL}$. Female sex (RR, $4.871 ; 95 \%$ CI, 1.352 to $17.544 ; \mathrm{p}=0.015)$ and low serum albumin levels (<3.3 g/dL; RR, 10.346; 95\% CI, 1.035 to 103.447 ; $\mathrm{p}=0.047$ ) were independent risk factors for selenium deficiency by multivariate logistic regression analysis (Table 5).

\section{DISCUSSION}

Our study showed that a considerable proportion of Korean patients with IBD had vitamin D, zinc, and selenium deficiencies. When compared with healthy controls, vitamin D levels were significantly lower in patients with IBD. Furthermore, we evaluated risk factors for these micronutrient deficiencies.

Currently, there is little evidence for routine evaluation of micronutrients. However, some literatures addressed importance of micronutrient in IBD patients. ${ }^{8}$ Analysis of these micro-nutrients does not lead additional risk or discomfort to the patients, as we used blood sample which was already taken for routine blood exam. Furthermore, these exams are relatively inexpensive. Based on this, we routinely monitored micronutrient in patients who visited our IBD clinic.

In the present study, the prevalence of suboptimal vitamin D levels in patients with IBD was $89.2 \%$, which was higher than that previously reported. ${ }^{23,28}$ This finding was consistent with those of previous studies in that a significantly higher percentage of Asians were found to have vitamin D deficiency compared to Caucasians. ${ }^{24,29}$ Female sex and presence of CD were independent risk factors for vitamin D deficiency in the patients of the present study. The incidence of vitamin D deficiency differed according to sex and this incidence might be affected by lifestyle, such as dietary intake or sunlight exposure. ${ }^{30} \mathrm{CD}$ is a known risk factor for vitamin D deficiency. ${ }^{31,32}$ Because the median duration of illness was only 5 months in this study, vitamin D deficiency might not be a consequence of disease; however, it might be associated with the pathogenesis of $\mathrm{CD}$. 23,28,33 Other risk factors mentioned in previous studies were long duration of disease, severe disease activity, high CRP levels, and use of corticosteroids, ${ }^{13}$ but we did not verify these variables.

We also evaluated the prevalence and risk factors for zinc deficiency. In a previous report, the mean serum zinc level in the Korean general population was $113.3 \pm 1.56 \mu \mathrm{g} / \mathrm{dL}{ }^{34}$ The mean level of serum zinc for IBD patients in our study was considerably lower than that of the Korean general population but relatively similar to that of Western IBD patients. ${ }^{17}$ The prevalence of zinc deficiency was $38.5 \%$ in this study. These data are very meaningful because little information is available regarding zinc deficiency in patients with IBD. In the present study, younger patients were at increased risk for zinc deficiency. Some reports suggest that younger age is correlated with severe disease and results in poor prognosis with IBD. ${ }^{35,36}$ High prevalence of zinc deficiency in younger patients might be affected by more severe disease activity, causing poor zinc absorption and increased intestinal loss of zinc, but evidence to date has been scanty. One important fact to note is that zinc deficiency not only is the consequence of poor dietary intake but also is correlated with the inflammatory process in IBD. This hypothesis is supported by the finding that zinc deficiency was highly prevalent even though sufficient supplements were provided through multivitamin additives to patients with IBD. ${ }^{37}$

The prevalence of selenium deficiency was 30.9\%. The mean serum selenium level in healthy Korean subject was $112.05 \pm 30.42 \mu \mathrm{g} / \mathrm{L}$, which was higher than that for healthy European adults. ${ }^{38-40}$ Similar to the general population, Korean patients with IBD showed higher mean levels of serum selenium compared with Caucasians. ${ }^{20}$ Soil selenium is important for determining content levels in food and influences serum selenium levels. ${ }^{41}$ This environmental factor might contribute to the difference in mean selenium levels in Koreans and Europeans. This is the first study to evaluate selenium deficiency in Asian patients with IBD. This study showed that a relatively high proportion of patients with IBD had selenium deficiency, even during early stages of disease. In the present study, risk factors for selenium deficiency were female sex and low levels of serum albumin $(<3.3 \mathrm{~g} / \mathrm{dL})$. In the general population, women tend to have lower selenium levels. ${ }^{42-44}$ Plasma albumin is correlated with plasma selenium; ${ }^{45}$ however, the mechanism is not well known. The optimal plasma selenium concentration for cancer prevention and decreased total mortality is considered to be $124 \mu \mathrm{g} / \mathrm{L} .^{46}$ Cancer prevention is a very important issue in IBD because prolonged, severe inflammation increases the risk of colitis-associated cancer. ${ }^{47}$ Little evidence exists regarding the cancer prevention effect of selenium in patients with IBD. Because dietary supplementation of selenium and optimization of selenoprotein biosynthesis led to favorable outcomes in murine IBD models, ${ }^{21,48}$ a positive role for selenium in cancer prevention is indicated. Aggressive management of selenium deficiency might be required.

The present study has several limitations. First, we could not measure disease activity because of the study's retrospective design. As a result, we could not directly evaluate the correlation between disease activity and micronutrient deficiency. Instead, we tried to assess disease severity by monitoring concurrent corticosteroids use and by measuring serum CRP levels. Second, we could not monitor dietary intake, which is an important factor affecting micronutrient status.

Beyond these limitations, our study has several strengths. This study is the first to evaluate micronutrient status in an Asian population with IBD; most other IBD studies have focused on Caucasian populations. Furthermore, we tried to reveal risk factors for micronutrient deficiency and succeeded in finding some contributors.

In conclusion, a substantial number of Korean patients with IBD had vitamin D, zinc, and selenium deficiencies. Our study 
suggests the need for monitoring these micronutrients in patients with IBD.

\section{CONFLICTS OF INTEREST}

No potential conflict of interest relevant to this article was reported.

\section{REFERENCES}

1. Mekhjian HS, Switz DM, Melnyk CS, Rankin GB, Brooks RK. Clinical features and natural history of Crohn's disease. Gastroenterology 1979;77(4 Pt 2):898-906.

2. Weisshof R, Chermesh I. Micronutrient deficiencies in inflammatory bowel disease. Curr Opin Clin Nutr Metab Care 2015;18:576581.

3. Harries $\mathrm{AD}$, Heatley RV. Nutritional disturbances in Crohn's disease. Postgrad Med J 1983;59:690-697.

4. Dawson AM. Nutritional disturbances in Crohn's disease. Br J Surg 1972;59:817-819.

5. Filippi J, Al-Jaouni R, Wiroth JB, Hébuterne X, Schneider SM. Nutritional deficiencies in patients with Crohn's disease in remission. Inflamm Bowel Dis 2006;12:185-191.

6. Hwang C, Ross V, Mahadevan U. Micronutrient deficiencies in inflammatory bowel disease: from A to zinc. Inflamm Bowel Dis 2012;18:1961-1981.

7. Massironi S, Rossi RE, Cavalcoli FA, Della Valle S, Fraquelli M, Conte D. Nutritional deficiencies in inflammatory bowel disease: therapeutic approaches. Clin Nutr 2013;32:904-910.

8. Yoon SY, Jung S. Nutritional support in patients with inflammatory bowel diseases. Intest Res 2013;11:243-249.

9. Holick MF. Vitamin D deficiency. N Engl J Med 2007;357:266281.

10. Siffledeen JS, Siminoski K, Steinhart H, Greenberg G, Fedorak RN. The frequency of vitamin D deficiency in adults with Crohn's disease. Can J Gastroenterol 2003;17:473-478.

11. Sentongo TA, Semaeo EJ, Stettler N, Piccoli DA, Stallings VA, Zemel BS. Vitamin D status in children, adolescents, and young adults with Crohn disease. Am J Clin Nutr 2002;76:1077-1081.

12. Leslie WD, Miller N, Rogala L, Bernstein CN. Vitamin D status and bone density in recently diagnosed inflammatory bowel disease: the Manitoba IBD cohort study. Am J Gastroenterol 2008;103:14511459.

13. Gilman J, Shanahan F, Cashman KD. Determinants of vitamin D status in adult Crohn's disease patients, with particular emphasis on supplemental vitamin D use. Eur J Clin Nutr 2006;60:889-896.

14. Li YC, Chen Y, Du J. Critical roles of intestinal epithelial vitamin $\mathrm{D}$ receptor signaling in controlling gut mucosal inflammation. J Steroid Biochem Mol Biol 2015;148:179-183.

15. Ooi JH, Li Y, Rogers CJ, Cantorna MT. Vitamin D regulates the gut microbiome and protects mice from dextran sodium sulfateinduced colitis. J Nutr 2013;143:1679-1686.
16. Livingstone C. Zinc: physiology, deficiency, and parenteral nutrition. Nutr Clin Pract 2015;30:371-382.

17. Vagianos K, Bector S, McConnell J, Bernstein CN. Nutrition assessment of patients with inflammatory bowel disease. JPEN J Parenter Enteral Nutr 2007;31:311-319.

18. Wong CP, Rinaldi NA, Ho E. Zinc deficiency enhanced inflammatory response by increasing immune cell activation and inducing IL6 promoter demethylation. Mol Nutr Food Res 2015;59:991-999.

19. Stoffaneller R, Morse NL. A review of dietary selenium intake and selenium status in Europe and the Middle East. Nutrients 2015;7:1494-1537.

20. Reimund JM, Hirth C, Koehl C, Baumann R, Duclos B. Antioxidant and immune status in active Crohn's disease: a possible relationship. Clin Nutr 2000;19:43-48.

21. Barrett CW, Singh K, Motley AK, et al. Dietary selenium deficiency exacerbates DSS-induced epithelial injury and AOM/DSS-induced tumorigenesis. PLoS One 2013;8:e67845

22. Barnett M, Bermingham E, McNabb W, et al. Investigating micronutrients and epigenetic mechanisms in relation to inflammatory bowel disease. Mutat Res 2010;690:71-80.

23. Ulitsky A, Ananthakrishnan AN, Naik A, et al. Vitamin D deficiency in patients with inflammatory bowel disease: association with disease activity and quality of life. JPEN J Parenter Enteral Nutr 2011;35:308-316.

24. Fu YT, Chatur N, Cheong-Lee C, Salh B. Hypovitaminosis D in adults with inflammatory bowel disease: potential role of ethnicity. Dig Dis Sci 2012;57:2144-2148.

25. Holick MF. 25-OH-vitamin D assays. J Clin Endocrinol Metab 2005;90:3128-3129.

26. Rosen CJ. Clinical practice: vitamin D insufficiency. N Engl J Med 2011;364:248-254.

27. Lim S, Kim MJ, Choi SH, et al. Association of vitamin D deficiency with incidence of type 2 diabetes in high-risk Asian subjects. Am J Clin Nutr 2013;97:524-530.

28. Ananthakrishnan AN, Cagan A, Gainer VS, et al. Normalization of plasma 25-hydroxy vitamin $\mathrm{D}$ is associated with reduced risk of surgery in Crohn's disease. Inflamm Bowel Dis 2013;19:19211927.

29. Choi HS. Vitamin D status in Korea. Endocrinol Metab (Seoul) 2013;28:12-16.

30. Shin YH, Kim KE, Lee C, et al. High prevalence of vitamin D insufficiency or deficiency in young adolescents in Korea. Eur J Pediatr 2012;171:1475-1480.

31. Kuwabara A, Tanaka K, Tsugawa N, et al. High prevalence of vitamin $\mathrm{K}$ and D deficiency and decreased BMD in inflammatory bowel disease. Osteoporos Int 2009;20:935-942.

32. Jahnsen J, Falch JA, Mowinckel P, Aadland E. Vitamin D status, parathyroid hormone and bone mineral density in patients with inflammatory bowel disease. Scand J Gastroenterol 2002;37:192199.

33. Joseph AJ, George B, Pulimood AB, Seshadri MS, Chacko A. 25 $(\mathrm{OH})$ vitamin D level in Crohn's disease: association with sun ex- 
posure \& disease activity. Indian J Med Res 2009;130:133-137.

34. Lee YC, Jung EJ, Hwang J, et al. A study on serum concentrations of antioxidant minerals in normal Korean adults. Korean J Nutr 1998;31:324-332.

35. Choi JH, Kim ES, Cho KB, et al. Old age at diagnosis is associated with favorable outcomes in Korean patients with inflammatory bowel disease. Intest Res 2015;13:60-67.

36. Romberg-Camps MJ, Dagnelie PC, Kester AD, et al. Influence of phenotype at diagnosis and of other potential prognostic factors on the course of inflammatory bowel disease. Am J Gastroenterol 2009;104:371-383.

37. Santucci NR, Alkhouri RH, Baker RD, Baker SS. Vitamin and zinc status pretreatment and posttreatment in patients with inflammatory bowel disease. J Pediatr Gastroenterol Nutr 2014;59:455-457.

38. Kim YJ, Galindev 0, Sei JH, et al. Serum selenium level in healthy Koreans. Biol Trace Elem Res 2009;131:103-109.

39. Van Cauwenbergh R, Robberecht H, Deelstra H, Picramenos D, Kostakopoulos A. Selenium concentration in serum of healthy Greek adults. J Trace Elem Electrolytes Health Dis 1994;8:99-109.

40. Dubois F, Teby A, Belleville F, Nabet P, Paysant P. Common values of serum selenium in a population in Eastern France. Ann Biol Clin (Paris) 1990;48:28-32.

41. Wang J, Li H, Yang L, et al. Distribution and translocation of selenium from soil to highland barley in the Tibetan Plateau KashinBeck disease area. Environ Geochem Health 2017;39:221-229.

42. Sunde RA, Paterson E, Evenson JK, Barnes KM, Lovegrove JA,
Gordon MH. Longitudinal selenium status in healthy British adults: assessment using biochemical and molecular biomarkers. Br J Nutr 2008;99 Suppl 3:S37-S47.

43. Galan P, Viteri FE, Bertrais S, et al. Serum concentrations of betacarotene, vitamins $\mathrm{C}$ and $\mathrm{E}$, zinc and selenium are influenced by sex, age, diet, smoking status, alcohol consumption and corpulence in a general French adult population. Eur J Clin Nutr 2005;59:1181-1190.

44. Błażewicz A, Klatka M, Astel A, et al. Serum and urinary selenium levels in obese children: a cross-sectional study. J Trace Elem Med Biol 2015;29:116-122.

45. Rannem T, Ladefoged K, Hylander E, Hegnhøj J, Jarnum S. Selenium status in patients with Crohn's disease. Am J Clin Nutr 1992;56:933-937.

46. Fairweather-Tait SJ, Bao Y, Broadley MR, et al. Selenium in human health and disease. Antioxid Redox Signal 2011;14:13371383.

47. Zhiqin W, Palaniappan S, Raja Ali RA. Inflammatory bowel disease-related colorectal cancer in the Asia-Pacific region: past, present, and future. Intest Res 2014;12:194-204.

48. Krehl S, Loewinger M, Florian S, et al. Glutathione peroxidase-2 and selenium decreased inflammation and tumors in a mouse model of inflammation-associated carcinogenesis whereas sulforaphane effects differed with selenium supply. Carcinogenesis 2012;33:620-628. 